\title{
sciendo
}

\section{Changes in Muscle Stiffness of the Trapezius Muscle after Application of Ischemic Compression into Myofascial Trigger Points in Professional Basketball Players}

\author{
by \\ Aleksandra Kisilewicz', Marcin Janusiak ${ }^{2}$, Rafał Szafraniec ${ }^{1}$, Małgorzata Smoter ${ }^{3}$, \\ Bogdan Ciszek4, Pascal Madeleine ${ }^{5}$, César Fernández-de-Las-Peñas' ${ }^{6}$, \\ Adam Kawczyński ${ }^{1}$
}

The study aimed to assess the effects of compression trigger point therapy on the stiffness of the trapezius muscle in professional basketball players (Part A), and the reliability of the MyotonPRO device in clinical evaluation of athletes (Part B). Twelve professional basketball players participated in Part $A$ of the study (mean age: $19.8 \pm 2.4$ years, body height $197 \pm 8.2 \mathrm{~cm}$, body mass: $91.8 \pm 11.8 \mathrm{~kg}$ ), with unilateral neck or shoulder pain at the dominant side. Part $B$ tested twelve right-handed male athletes (mean $\pm S D$; age: $20.4 \pm 1.2$ years; body height: $178.6 \pm 7.7 \mathrm{~cm}$; body mass: $73.2 \pm 12.6 \mathrm{~kg}$ ). Stiffness measurements were obtained directly before and after a single session trigger point compression therapy. Measurements were performed bilaterally over 5 points covering the trapezius muscle. The effects were evaluated using a full-factorial repeated measure ANOVA and the Bonferroni post-hoc test for equal variance. A $p$-value $<.05$ was considered significant. The RM ANOVA revealed a significant decrease in muscle stiffness for the upper trapezius muscle. Specifically, muscle stiffness decreased from $243.7 \pm 30.5$ to $215.0 \pm 48.5 \mathrm{~N} / \mathrm{m}(11.8 \%)$, ( $p=$ .008) (Part A). The test-retest relative reliability of trapezius muscle stiffness was found to be high (ICC from 0.821 to 0.913 for measurement points). The average SEM was $23.59 \mathrm{~N} / \mathrm{m}$ and the MDC $65.34 \mathrm{~N} / \mathrm{m}$, respectively (Part B). The present study showed that a single session of compression trigger point therapy can be used to significantly decrease the stiffness of the upper trapezius among professional basketball players.

Key words: myofascial pain syndrome, soft tissue therapy, sports medicine, myotonometry.

\section{Introduction}

The systematic practice of team sports at an elite level, such as basketball, requiring overhead or repetitive upper extremity movements is often associated with a higher risk for injury (Hume et al., 2006). These injuries can force a player out of competition for long periods of time or cause a player to resign from a professional sporting career. In recent years, training loads have significantly increased, placing greater demands on musculoskeletal structures. Soft tissue therapy techniques have, therefore, become invaluable elements of

\footnotetext{
1 - Department of Sport Science, University School of Physical Education in Wroclaw; Wrocław, Poland.

2 - Department of Physical Education, University School of Physical Education in Wroclaw; Wrocław, Poland.

3 - Department of Biostructure, University School of Physical Education in Wroclaw; Wroctaw, Poland.

4 - Department of Anatomy, Medical University of Warsaw; Warszawa, Poland.

5 - Department of Health Science and Technology, Sport Sciences, Aalborg University, Aalborg, Denmark

6 - Department of Physical Therapy, Occupational Therapy, Rehabilitation and Physical Medicine, King Juan Carlos University; Madrid, Spain.
} 
treatment programs of professional athletes (Vahimets et al., 2006).

Myofascial pain syndrome (MPS) is mainly featured by myofascial trigger points (MTrPs) and is a musculoskeletal disorder that can be developed with any type of sports training and performance. The shoulder and scapula regions including the upper trapezius muscle are the most common areas developing myofascial pain syndrome among overhead sport activities (Hidalgo-Lozano et al., 2013). MTrPs are characterized by the presence of a palpable taut band or a spot within a skeletal muscle (Barbero et al., 2013). The local inflammation caused by MTrPs can negatively affect surrounding soft tissues, resulting in impairment of the entire muscle and surrounding fascia. These negative effects can further be transferred, through the myofascial chain, to distant tissues, inducing the referred pain that is the main characteristic of MPS. The presence of MTrPs is, therefore, considered to be the first sign of overloading of a muscle (Ge et al., 2011).

In recent years, the interest in finding effective MPS therapy has been the subject of many scientific investigations (Dolan and Mendel, 2004; Rigby and Draper, 2017). However, local ischemic compression still remains the most common and non-invasive therapy currently used for the treatment of MTrPs (Cagnie et al., 2015). It is suggested that ischemic compression could lead to normalization of biomechanical properties of muscle fibers, restoring the normal functional condition of the muscle and most likely decreasing the risk of injury (Simons, 2004). The local therapeutic effects of ischemic compression include stimulation of mechanoreceptors, with associated attenuation of pain signals, mostly due to a depletion of specific neurotransmitters, and a temporary obstruction of the local blood flow, followed by a rapid inflow of oxygenated blood to the area upon the release of the pressure (Hou et al., 2002). As such, the treatment of MTrPs by ischemic compression produces rapid pain relief, as well as normalization of the biomechanical properties of the local muscle fibers, which restores the normal functional condition of the muscle including improved range of motion and lower risk of injury (Renan-Ordine et al., 2011).

Although subjective, palpation remains the most popular physical method to evaluate muscle tone in clinical practice. Objective measures have been developed to quantitatively identify local changes in muscle tension, including electromyography and ultrasonography. However, as these techniques require technical equipment and complicated procedures, they are still not really practical in clinical practice (Marusiak et al., 2011). Therefore, there is a need to introduce a new method for measuring the mechanical properties of soft tissues in science, sports and medicine. Especially, in vivo measurement of muscle biomechanical variables including muscle stiffness are of particular interest (Dieterich et al., 2017). MyotonPRO is a non-invasive approach to measure stiffness, with good to excellent reliability reported in healthy individuals (Aird et al., 2012). Repeated measurement of muscle stiffness can provide a useful index of the effectiveness of a therapeutic intervention, such as ischemic compression (Gavronski et al., 2007). To the best of our knowledge, no study has investigated changes in muscle stiffness after the application of ischemic compression. Therefore, the aim of the current study was to use quantitative myotonometry to investigate A) the changes in muscle stiffness after the application of ischemic compression over MTrPs in the trapezius muscle in a sample of professional basketball players; B) the test-retest reliability of MyotonPRO for measurements of muscle stiffness. We hypothesized that ischemic compression would produce a decrease in the stiffness of the trapezius muscle in the area covered by MTrPs.

\section{Methods}

\section{Participants}

In part A) (trigger point therapy), twelve male players from the elite Polish basketball league were included in the study (mean $\pm \mathrm{SD}$; age: $19.8 \pm 2.4$ years; body height: $197 \pm 8.2 \mathrm{~cm}$; body mass: $91.8 \pm 11.8 \mathrm{~kg}$ ).

In part B) (test-retest experiment), twelve right-handed male athletes (mean \pm SD; age: $20.4 \pm$ 1.2 years; body height: $178.6 \pm 7.7 \mathrm{~cm}$; body mass: $73.2 \pm 12.6 \mathrm{~kg}$ ) volunteered to participate.

To be considered (in part A), participants should fulfil the following criteria: 1 , training work loads of at least 20 hours per week; 2, regular participation in international competition 
and training, within the FIBA Europa Cup; 3, presence of unilateral neck or shoulder pain at the dominant side; and, 4, active MTrPs in the dominant trapezius muscle. The exclusion criteria were: 1 , pain in the contralateral shoulder; 2, cervicothoracic spinal pathology.

A MTrP was diagnosed using the following criteria: presence of a taut band or a spot and the reproduction of local pain at the point and of referred pain. The number of identified MTrPs and their location were based on a standard MTrPs position, described in the literature (Barbero et al., 2013), and individual examination. It aimed to eliminate the possible inclusion of MTrPs from other muscles within the investigated region. The average number of MTrPs for each participant was $5 \pm 1$. The main criterion for exclusion was a recent injury to the shoulder or neck, which could affect the measured variables of muscle stiffness. All participants provided informed consent, and the study was approved by the Ethics Committee of the University School of Physical Education in Wroclaw and conducted in accordance with the Declaration of Helsinki.

\section{Measures}

Dynamic stiffness is defined as the resistance of soft tissue to a contraction or an external force that deforms its initial shape (Schneider et al., 2015; Viir et al., 2006). Dynamic stiffness of both trapezius muscles was quantified using the damped oscillation method of the MyotonPRO device. The probe at the end of the device was placed perpendicularly to the surface of the skin overlying the trapezius muscle. Slight pressure was applied between the probe and the surface of the skin, and a short mechanical impulse $(0.4 \mathrm{~N}$ for $15 \mathrm{~ms})$, with a constant precompression force of $0.18 \mathrm{~N}$, was delivered to the tissue directly under the probe. The mechanical impulse generates damped oscillations within the muscle, which are recorded by an accelerometer within the probe. The device processes the raw measurement of oscillations to provide the resultant oscillation curve from which dynamic stiffness is calculated and displayed. Based on the accelerometer output, stiffness was derived as follows: the period $\mathrm{T}$ was defined as the time elapsed between the first two adjacent acceleration peaks following the mechanical impulse. The oscillation frequency $f$ was calculated from the equation: $f=\mathbf{1} / \mathrm{T}$. The angular frequency $\omega(\omega=2 \pi f)$, is related to stiffness $K$ and mass $\mathrm{m}$, and it allows you to calculate stiffness: $\mathrm{K}=\omega^{2} \mathrm{~m}$. Substituting into: $\mathrm{K}=4 \pi^{2} f^{2} \mathrm{~m}$ (Sohirad et al., 2017).

\section{Design and Procedures}

All outcomes were obtained with the participant lying in a prone position, with the upper extremities placed along the trunk, and the forearms placed in a position midway between supination and pronation. Myotonometric measurements were performed: Part A) at one day: before and immediately after MTrP therapy; Part B) at day 0 (test) and day 1 (retest). All measurements of muscle stiffness were obtained at 5 standardized points on the trapezius muscle, bilaterally (Table 1) (Figure 1) (Nie et al., 2005), by the same operator. A second trained physiotherapist was responsible for the treatment of the participants. The dominant side was treated by MTrP therapy and the non-dominant one served as a contralateral measurement of the therapy effects.

After MTrPs localization, ischemic compression was sequentially performed at each MTrP until pain relief was achieved, on average for $40 \mathrm{~s}$. MTrPs located in the upper trapezius were treated using a pinch grip (Figure 2). MTrPs located in the middle and lower parts of the trapezius muscle were treated using a flat compression technique (Figure 3). The selection of the grip type was based on the anatomical structure of muscle, with no influence on thereapy efficacy. The physiotherapist applied gradually increasing pressure to the MTrP until the sensation of pressure became one of pressure and pain. At that moment, the pressure was maintained until the pain eased by around $50 \%$ at which time pressure was increased until discomfort appeared again and sustained, but for no longer than 2 min (Cagnie et al., 2015).

\section{Statistical Analysis}

Part A) Measurements (before and immediately after treatment) and points (01-05 marked on the trapezius muscle) were introduced as within subject factors in a full-factorial repeated measure analysis of variance (RMANOVA) conducted on stiffness values. The right (intervention) and left (contralateral) side of the trapezius muscle were included as between subject effect. Bonferroni adjustment for multiple 
comparisons was used as a post hoc test. The normality of the data distribution was checked with the Shapiro-Wilk test. In all tests, $p$-value < 0.05 was considered significant. The data are presented as means and SD in the text and figures. All calculations were performed using PASW® Statistics (SPPS Inc.).

Part B) The relative and absolute reliability of stiffness measurements was computed using intra-class correlation coefficients (ICC), standard error of measurement (SEM) and minimum detectable change (MDC). A Bland-Altman plot was used to analyze the level of agreement (the $95 \%$ confidence interval) between the test and retest session. The relative reliability was calculated by a 2-way fixed ICC 2,1 (for absolute agreement). The SEM was calculated as: $S D \times \sqrt{1-I C C}$ and MDC as $S E M \times 1.96 \times \sqrt{2}$, respectively.

\section{Results}

Part A) Table 2 shows mean and SD data of muscle stiffness of each point before and after treatment. The RM ANOVA revealed a significant measurement $\times$ interaction $(\mathrm{F}=4.883 ; p=.03)$ for changes in muscle stiffness between measurements. Muscle stiffness decreased significantly in the upper $(p=.03)$, while no significant differences were found in the middle (MT) $(p=.40)$ and lower trapezius $(p=.29)$. Muscle stiffness (mean of points 01-02) decreased from $243.7 \pm 30.5$ before treatment to $215.0 \pm 48.5$ $\mathrm{N} / \mathrm{m}$ immediately after ischemic compression $(p=$ $.01)$, showing a decrease of $11.8 \%$ in the upper portion of the trapezius muscle. On the contrary, stiffness of the middle and lower trapezius (mean of point 03 to 05 ) was not changed significantly $(357.5 \pm 139.7 \mathrm{~N} / \mathrm{m}$ before treatment and $331.0 \pm$ $88.1 \mathrm{~N} / \mathrm{m}$ after ischemic compression; $p=.27$ ).

No significant change in dynamic stiffness in the non-dominant (untreated) trapezius muscle was found. The mean value was $283.12 \pm 103.1$ $\mathrm{N} / \mathrm{m}$ before treatment and $271.38 \pm 97.3 \mathrm{~N} / \mathrm{m}$ after compression of MTrPs on the non-dominant side.

Part B) The test-retest relative reliability of trapezius muscle stiffness was found to be high (ICC from 0.821 to 0.913 for all measurement points). The average SEM was $23.59 \mathrm{~N} / \mathrm{m}$ and the MDC $65.34 \mathrm{~N} / \mathrm{m}$ (Table 3). The visual analysis of Bland and Altman's plots indicated no significant difference in stiffness values between test- retest sessions $(p=.451)$, with the mean value close to 0 $(.049 \mathrm{~N} / \mathrm{m})$ (Figure 4$)$.

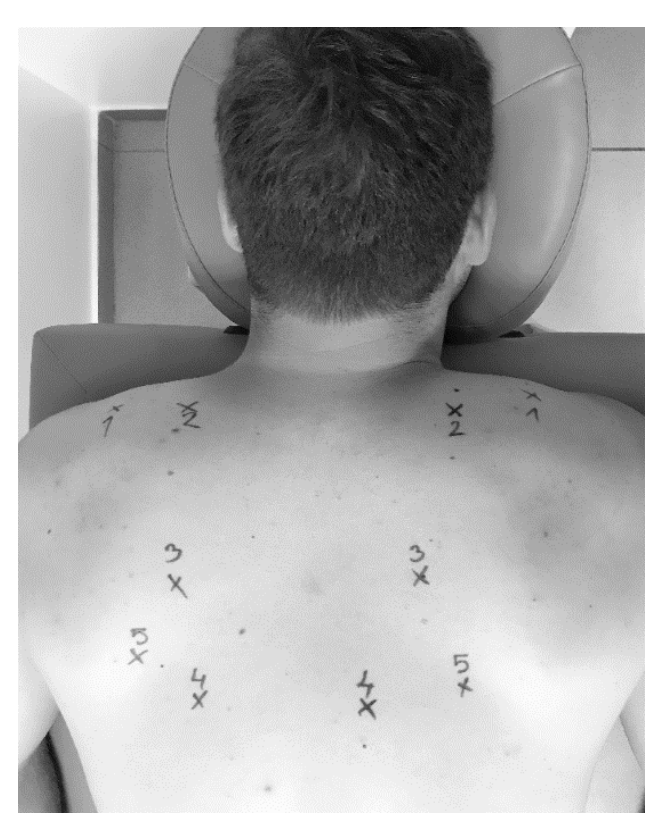

Figure 1

The points of assessment on the trapezius muscle. 

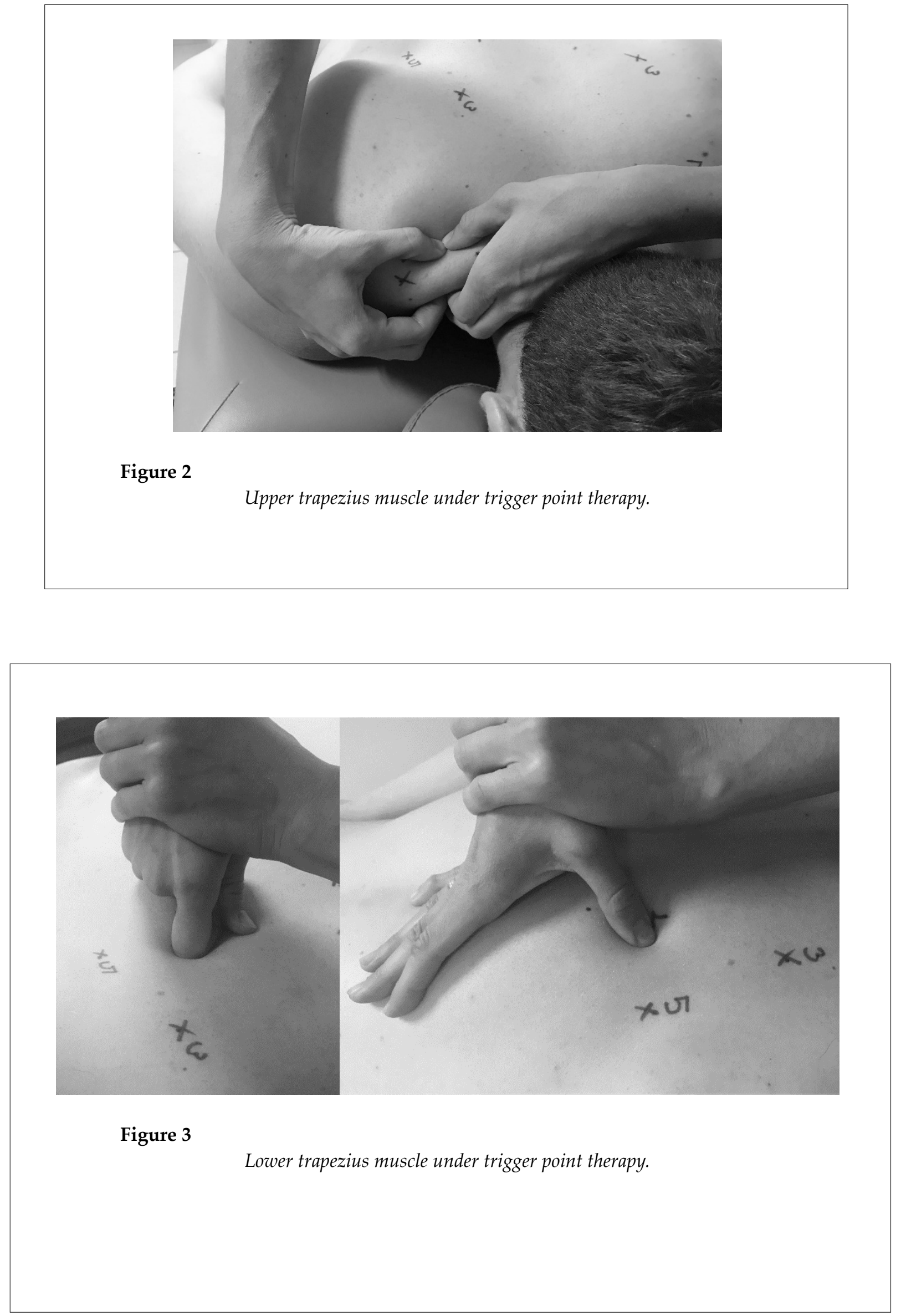


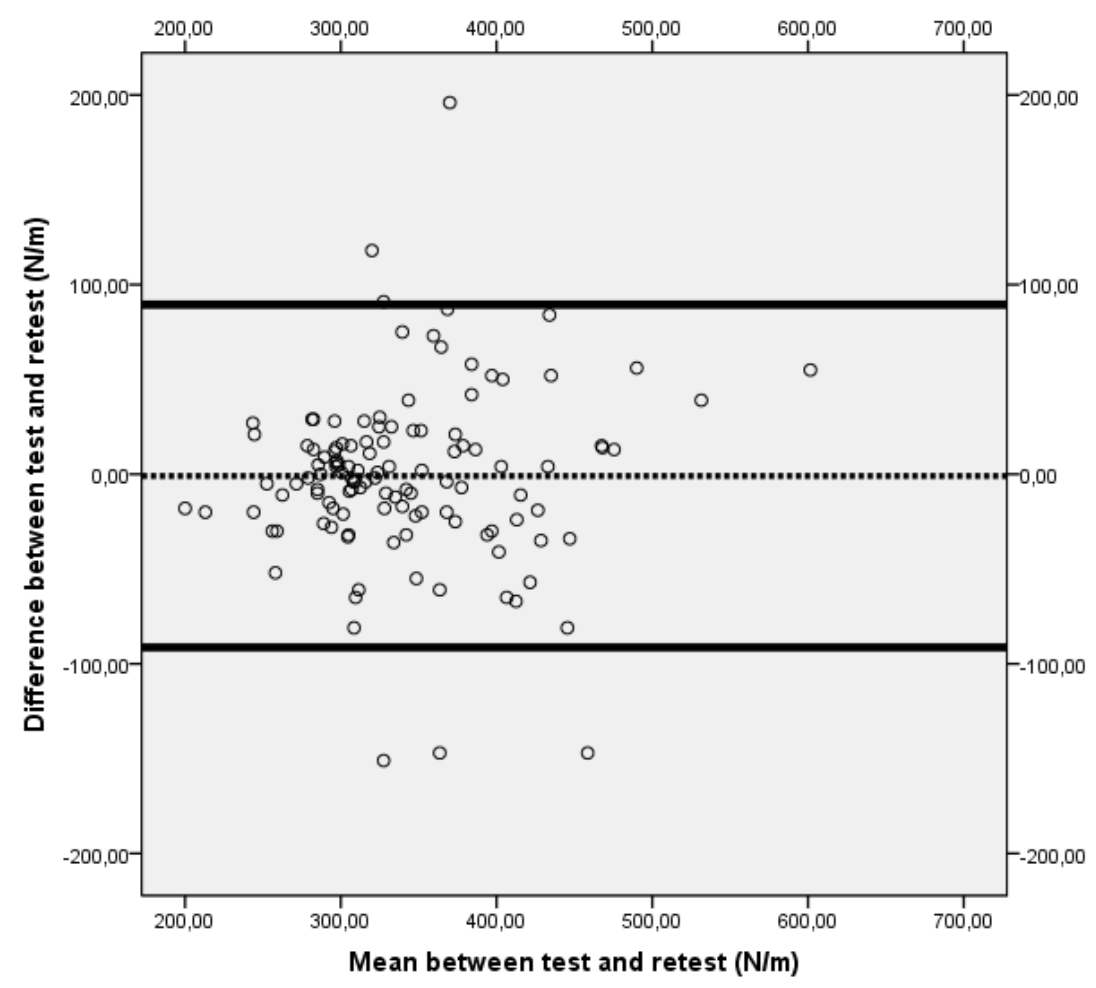

Figure 4

Bland and Altman analyses plotted for test and retest measurements of trapezius muscle stiffness $(\mathrm{N} / \mathrm{m})$.

Table 1

Description of measurement points locations.

\begin{tabular}{|c|c|c|}
\hline $\begin{array}{l}\text { Point } \\
\text { number }\end{array}$ & $\begin{array}{l}\text { Trapezius muscle } \\
\text { part }\end{array}$ & Localization \\
\hline 01 & upper & $\begin{array}{l}\text { the end-points of a line connecting the spinous process of } C 7 \\
\text { and the acromion, distally, from the mid-point of the muscle } \\
\text { belly. }\end{array}$ \\
\hline 02 & upper & $\begin{array}{l}\text { the end-points of a line connecting the spinous process of } \mathrm{C} 7 \\
\text { and the acromion, proximally, from the mid-point of the } \\
\text { muscle belly. }\end{array}$ \\
\hline 03 & middle & $\begin{array}{l}\text { the mid-point of a line connecting the spinous process of } \mathrm{T} 4 \\
\text { to the medial border of spine of the scapulae }\end{array}$ \\
\hline 04 & lower & $\begin{array}{l}\text { the mid-point of a line connecting the spinous process of } \mathrm{T} 6 \\
\text { to the medial border of spine of the scapulae }\end{array}$ \\
\hline 05 & lower & $\begin{array}{l}\text { the mid-point of the lateral border of the lower fibers of the } \\
\text { trapezius }\end{array}$ \\
\hline
\end{tabular}


Table 2

Mean $\pm S D$ trapezius muscle stiffness $(N / m)$ before and after trigger point therapy.

\begin{tabular}{|c|c|c|c|c|c|}
\hline \multirow{2}{*}{$\begin{array}{l}\text { Muscle } \\
\text { Stiffness (N/m) }\end{array}$} & \multicolumn{3}{|c|}{ Trapezius muscle on the dominant side } & \multicolumn{2}{|c|}{ Left side of trapezius } \\
\hline & Before therapy & After therapy & $\begin{array}{l}\text { Change } \\
\text { scores }\end{array}$ & $\begin{array}{l}\text { Before } \\
\text { therapy }\end{array}$ & After therapy \\
\hline Point 1 & $232.0 \pm 29.7^{*}$ & $217.5 \pm 46.9^{*}$ & $-14.5 \pm 45.9$ & $289.92 \pm 140.1$ & $272.75 \pm 133.7$ \\
\hline Point 2 & $269.0 \pm 42.1^{*}$ & $240.2 \pm 105.9^{*}$ & $-28.8 \pm 70.3$ & $276.33 \pm 49.9$ & $270.00 \pm 43.8$ \\
\hline Point 3 & $405.3 \pm 192.1$ & $337.7 \pm 119.4$ & $-67.7 \pm 216.7$ & $373.33 \pm 107.2$ & $374.33 \pm 118.4$ \\
\hline Point 4 & $347.5 \pm 110.4$ & $326.0 \pm 73.4$ & $-21.5 \pm 84.6$ & $402.33 \pm 175.2$ & $420.33 \pm 175.1$ \\
\hline Point 5 & $331.7 \pm 89.3$ & $329.4 \pm 70.4$ & $-2.3 \pm 73.4$ & $355.75 \pm 61.4$ & $357.83 \pm 67.3$ \\
\hline
\end{tabular}

*Significant difference between stiffness values before and after trigger point therapy

Table 3

Intraclass correlation coefficients (ICC), standard error of measurement (SEM) and minimum detectable change (MDC) for trapezius muscle stiffness assessed over 10 measurement points.

\begin{tabular}{lccc}
\hline Points & ICC $(95 \% \mathrm{CI})$ & SEM $(\mathrm{N} / \mathrm{m})$ & MDC $(\mathrm{N} / \mathrm{m})$ \\
\hline P01 right & $0.831(0.447-0.950)$ & 26.98 & 74.74 \\
P02 right & $0.733(0.020-924)$ & 16.48 & 45.65 \\
P03 right & $0.813(0.328-0.947)$ & 17.60 & 48.75 \\
P04 right & $0.885(0.613-0.967)$ & 18.79 & 52.04 \\
P05 right & $0.834(0.456-0.951)$ & 17.06 & 47.27 \\
P01 left & $0.467(-0.401-0.831)$ & 41.57 & 115.14 \\
P02 left & $0.229(-0.698-0.734)$ & 46.02 & 127.47 \\
P03 left & $0.963(0.871-0.989)$ & 12.52 & 34.68 \\
P04 left & $0.820(0.374-0.948)$ & 28.02 & 77.61 \\
P05 left & $0.926(0.745-0.979)$ & 10.84 & 30.02 \\
\hline
\end{tabular}




\section{Discussion}

The current study found a significant decrease in muscle stiffness in the upper, but not middle or lower portion, of the trapezius muscle in a sample of elite basketball players after a single session of ischemic compression over active MTrPs. The relative reliability of stiffness measurements was found to be almost perfect according to Landis and Koch (1977). The Bland and Altman's plots analysis showed no difference in stiffness values between the test and retest, suggesting no proportional bias and very good agreement between sessions.

When designing our study we assumed that increased muscle stiffness could contribute to functional impairment of the shoulder region, and increase the risk of injury. Leong and colleagues (2016) examined upper trapezius stiffness in overhead athletes with and without rotator cuff tendinopathy. Their findings suggested that monitoring and maintenance of upper trapezius stiffness are essential for the prevention of rotator cuff tendinopathy. The presence of trauma and consequently, a significantly higher degree of stiffness, increase the limitation of preoperative joint range of motion (Seo et al., 2012). Bailey et al. (2015) suggested that reducing muscle stiffness could be beneficial for improving shoulder range of motion. As they stated the deficits in range of motion were identified as injury risk factors among baseball athletes. Therefore, potential interventions, which could lead to reduce muscle stiffness, could help these team sport players.

The need for an objective evaluation of stiffness reduction after MTrPs treatment has recently been investigated (Chen et al., 2016; Maher et al., 2013). Similarly to our findings, these studies reported a significant decrease of upper trapezius muscle stiffness after MTrP therapy. The study conducted by Ballyns et al. (2011), in agreement with our research also confirmed higher stiffness of upper trapezius muscle and a lower pressure pain threshold, associated with MTrPs. Moreover, the abnormal metabolic conditions associated with MTrPs can lead to chronic pain and inflammation (Shah and Gillians, 2005). In accordance with our assumptions, Kamali et al. (2018) also acknowledged the relationship between chronic musculoskeletal shoulder disorders and MTrPs, particularly in the upper trapezius. Instead of ischemic compression, they proposed a different therapeutic approach, by the dry needling of MTrPs. However, as they pointed out the direct application of dry needling in the upper trapezius could cause local lesions and severe post-needle soreness. Therefore, they proposed an alternative approach of infraspinatus muscle dry needling and proved it equally effective in decreasing pain and disability in athletes with shoulder pain. Our conclusions regarding ischemic compression were similar. Therefore, the therapy of MTrPs can contribute to pain relief and reduction of stiffness in agreement with the present findings of the upper trapezius (Shah et al., 2008).

The absence of significant therapeutic effect of ischemic compression for MTrPs within the middle and lower trapezius is difficult to interpret, as the majority of existing research regarding MTrP treatment has only focused on the upper trapezius (Draper et al., 2010; Kelencz et al., 2011). Because of trapezius muscle anatomical structure and location, selective and reliable measures of biomechanical variables are easier to obtain for the upper portion than from the middle and lower portions of the muscle. Johnson and Pandyan (2005) reported significant differences in EMG activity between the upper and middle fibers of the trapezius muscle under controlled loading conditions. Kawczynski et al. (2012) showed higher sensitivity to pressure pain for the upper trapezius underlining the importance of the upper portion of the trapezius muscle in neckshoulder disorders.

It is also possible that the lack of changes in stiffness in the middle and lower trapezius was caused by their tendency to decreased resting muscle tone. In particular, increased activation of the upper trapezius, combined with decreased control of the lower trapezius are responsible for the abnormal scapula position and motion (Cools et al., 2007). For the rehabilitation or training in athletes with scapula impingement or dyskinesis, it is most important to get efficient and independent activation of the middle and lower trapezius, while minimizing activation of upper muscle fibers (Oliver et al., 2016). The correlation between a weakened activity of the middle and lower trapezius, and neck pain was also confirmed by other authors (Petersen et al., 2015). Moreover, neck and shoulder pain is often associated with forward head posture. It derives 
form weakness of scapular retractors such as lower trapezius fibers, and shortened length of the upper trapezius, with its tendency to hypertonicity and to decrease muscle elasticity (Bae et al., 2016). On the contrary, and in the agreement with the above mentioned authors, we acknowledge that the muscle tension of the upper trapezius tends to increase, and therefore, as the result of these divergences, the response to therapy of the three portions of the trapezius may be different.

There are several limitations to the current study. First, the number of MTrPs for upper fibers of trapezius muscle was generally higher for all participants, compared with the middle and lower parts. This could have influenced the effectiveness of MTrP therapy. Second, the small sample size could also result in the lack of significant differences in stiffness for the middle and lower trapezius. Third, the athletes included in this study were all professional basketball players and future studies could target other groups of athletes to enable a broader generalization of the current findings.
Finally, the causality cannot be inferred from a pre- to post-test study design.

\section{Conclusions}

Our study confirms that a single treatment session of active MTrPs with ischemic compression causes a decrease in muscle stiffness of the upper portion of the trapezius muscle. A decrease of muscle stiffness has been suggested to improve deficits in range of motion and thereby lower the risk of injuries among baseball players (Bailey et al., 2015). Within the present study, we provided an objective confirmation of the effectiveness of MTrP therapy from a clinical perspective. This treatment may bring immediate pain relief, which is a very important aspect of the treatment and rehabilitation of athletes. Furthermore, it is worth emphasizing that a reduction in muscle stiffness can be objectively quantified using a MyotonPRO device. This opens important clinical possibilities for the diagnostic and treatment of MTrPs outstanding current limitations of the palpation method (Myburgh et al., 2008).

\section{References}

Aird L, Samuel D, Stokes M. Quadriceps muscle tone, elasticity and stiffness in older males: Reliability and symmetry using the MyotonPRO. Archives of Gerontology and Geriatrics, 2012; 55(2): E31-E39

Bae W-S, Lee H-O, Shin J-W, Lee K-C. The effect of middle and lower trapezius strength exercises and levator scapulae and upper trapezius stretching exercises in upper crossed syndrome. J Phys. Ther Sci, 2016: 28: 1636-1639

Bailey LB, Shanley E, Hawkins R, Beattie PF, Fritz S, Kwartowitz D, Thigpen CA. Mechanisms of Shoulder Range of Motion Deficits in Asymptomatic Baseball Players. Am J Sports Med, 2015; 43(11): 2783-2793

Ballyns JJ, Shah JP, Hammond J, Gebreab T, Gerber LH, Sikdar S. Objective sonographic measures for characterizing myofascial trigger points associated with cervical pain. J Ultrasound Med, 2011; 30: 13311340

Barbero M, Cescon C, Tettamanti A, Leggero V, Macmillan F, Coutts F, Gatti R. Myofascial trigger points and innervation zone locations in upper trapezius muscles. BMC Musculoskel Disord, 2013; 14: 179

Cagnie B, Castelein B, Pollie F, Steelant L, Verhoeyen H, Cools A. Evidence for the use of ischemic compression and dry needling in the management of trigger points of the upper trapezius in patients with neck pain: A systematic review. Am J Phys Med Rehabil, 2015; 94: 573-583

Chen Q, Wang HJ, Gay RE, Thompson JM, Manduca A, An KN, Ehman RE, Basford JR. Quantification of Myofascial Taut Bands. Arch Phys Med Rehabil, 2016; 97(1): 67-73

Cools AM, Declercq GA, Cambier DC, Mahieu NM, Witvrouw EE. Trapezius activity and intramuscular balance during isokinetic exercise in overhead athletes with impingement symptoms. Scand J Med Sci Sports, 2007; 17: 25-33 
Dieterich AV, Andrade RJ, Le Sant G, Falla D, Petzke F, Hug F, Nordez A. Shear wave elastography reveals different degrees of passive and active stiffness of the neck extensor muscles. Eur J Appl Physiol, 2017; 117(1): 171-178

Dolan MG, Mendel MC. Clinical Application of Electrotherapy. Athletic Therapy Today, 2004; 9(5): 11-16

Draper DO, Mahaffey C, Kaiser D, Eggett D, Jarmin J. Thermal ultrasound decreases tissue stiffness of trigger points in upper trapezius muscles. Physiother Theory Pract, 2010; 26(3): 167-172

Gavronski G, Veraksits A, Vasar E, Maaroos J. Evaluation of viscoelastic parameters of the skeletal muscles in junior triathletes. Physiol Meas, 2007; 28(6): 625-637

Ge H-Y, Fernandez-de-las-Penas C, Yue S-W. Myofascial trigger points: spontaneous electrical activity and its consequences for pain induction and propagation. Chin Med, 2011; 6: 13

Hidalgo-Lozano A, Fernandez-de-las-Penas C, Calderon-Soto C, Domingo-Camara A, Madeleine P, ArroyoMorales M. Elite swimmers with and without unilateral shoulder pain: mechanical hyperalgesia and active/latent muscle trigger points in neckshoulder muscles. Scand J Med Sci Sports, 2013; 23(1): 66-73

Hou CR, Tsai LC, Cheng KF, Chung KC, Hong CZ. Immediate effects of various physical therapeutic modalities on cervical myofascial pain and trigger-point sensitivity. Arch Phys Med Rehabil, 2002; 83(10): 1406-1414

Hume PA, Reid D, Edwards T. Epicondylar injury in sport - Epidemiology, type, mechanisms, assessment, management and prevention. Sports Med, 2006; 36: 151-170

Johnson GR, Pandyan AD. The activity in the three regions of the trapezius under controlled loading conditions - an experimental and modelling study. Clin Biomech, 2005; 20(2): 155-161

Kamali F, Sinaei E, Morovati M. Comparison of Upper Trapezius and Infraspinatus Myofascial Trigger Point Therapy by Dry Needling in Overhead Athletes With Unilateral Shoulder Impingement Syndrome. J Sport Rehabil, 2018; 24: 1-24

Kawczynski A, Samani A, Fernandez-de-las-Penas C, Chmura J, Madeleine P. Sensory Mapping of the Upper Trapezius Muscle in Relation to Consecutive Sessions of Eccentric Exercise. J Strength Condit Res, 2012, 26(6): 1577-1583

Kelencz CA, Tarini VAF, Amorim CF. Trapezius upper portion trigger points treatment purpose in positional release therapy with electromyographic analysis. N A J Med Sci, 2011; 3(10): 451-455

Landis JR, Koch GG. An application of hierarchical kappa-type statistics in the assessment of majority agreement among multiple observers. Biometrics, 1977; 33(2): 363-74

Leong HT, Hug F, Fu SN. Increased Upper Trapezius Muscle Stiffness in Overhead Athletes with Rotator Cuff. Tendinopathy. PLoS ONE, 2016; 11(5): e0155187

Maher RM, Hayes DM, Shinohara M. Quantification of dry needling and posture effects on myofascial trigger points using ultrasoundshear-wave elastography. Arch Phys Med Rehabil, 2013; 94(11): 21462150

Marusiak J, Jaskolska A, Budrewicz S, Koszewicz M, Jaskólski A. Increased muscle belly and tendon stiffness in patients with Parkinson's disease as measured by myotonometry. Mov Disord, 2011; 26(11): 21192122

Myburgh C, Larsen AH, Hartvigsen J. A systematic, critical review of manual palpation for identifying myofascial trigger points: evidence and clinical significance. Arch Phys Med Rehabil, 2008; 89: 1169-1176

Nie HL, Kawczynski A, Madeleine P, Arendt-Nielsen L. Delayed onset muscle soreness in neck/shoulder muscles. Eur J Pain, 2005; 9(6): 653-660

Oliver G, Henning L, Plummer H. Scapula muscle activations during overhead throwing holds. Int. J Athl Ther Trai, 2016; 21(3): 42-46

Petersen SM, Cook CE, Donaldson MB, Hassen A, Ellis A, Learman K. The effect of manual therapy with augmentative exercises for neck pain: A randomized clinical trial. J Man Manip Ther, 2015; 23(5): 264275 
Renan-Ordine R, Alburquerque-Sendin F, de Souza DP, Cleland JA, Fernández-de-Las-Peñas C. Effectiveness of myofascial trigger point manual therapy combined with a self-stretching protocol for the man- agement of plantar heel pain: a randomized controlled trial. J Orthop Sports Phys Ther, 2011; 41(2): 4143-4150

Rigby JH, Draper DO. Effects of Long Duration Low Intensity Ultrasound for Active Trapezius Trigger Points: A Randomized Clinical Trial. J Sport Rehabil, 2017; 9: 1-17

Schneider S, Peipsi A, Stokes M, Knicker A, Abeln V. Feasibility of monitoring muscle health in microgravity environments using Myoton technology. Med Biol Eng Comput, 2015; 53(1): 57-66

Seo SS, Choi JS, An KC, Kim JH, Kim SB. The factors affecting stiffness occurring with rotator cuff tear. J Shoulder Elbow Surg, 2012; 21(3): 304-309

Shah JP, Danoff JV, Desai MJ, , Parikh S, Nakamura LY, Phillips TM, Gerber LH. Biochemicals associated with pain and inflammation are elevated in sites near to and remote from active myofascial trigger points. Arch Phys Med Rehabil, 2008; 89: 16-23

Shah K, Gillians E. Uncovering the biochemical milieu of myofascial trigger points using in vivo microdialysis: an application of muscle pain concepts to myofascial pain syndrome. J Bodyw Mov Ther, 2005; $12: 371-384$

Simons DG. Review of enigmatic MTrPs as a common cause of enigmatic musculoskeletal pain and dysfunction. J Electromyogr Kinesiol, 2004; 14: 95-107

Sohirad S, Wilson D, Waugh Ch, Finnamore E, Scott A. Feasibility of using a hand-held device to characterize tendon tissue biomechanics. PLoS ONE, 2017; 12(9): e0184463

Vahimets M, Gapeyeva H, Ereline J, Paasuke M, Kaasik P, Vain A. Influence of trigenics myoneural treatment on lower extremities' muscle tone and viscous-elastic properties in young basketball players. Acta Acad Olymp Eston, 2006; 14(1/2): 49-68

Viir R, Laiho K, Kramarenko J, Mikkelsson M. Repeatability of trapezius muscle tone assessment by a myometric method. J Mech Med Biol, 2006; 6(2): 215-228

\section{Corresponding author:}

\section{Adam Kawczyński}

Department of Sport Science,

University School of Physical Education in Wroclaw;

Wrocław, Poland

E-mail: kawczynski.a@gmail.com 